\title{
Experimental and Numerical Study on the Behaviour of a Steel Beam under Ceiling Exposed to a Localized Fire
}

\author{
A. PCHELINTSEV \\ All-Russian Research Institute for Fire Protection \\ VNIIPO, Balashikha-3, Moscow Region 143900, Russia \\ Y. HASEMI \\ Building Research Institute \\ Ministry of Construction \\ Tsukuba, Ibaraki, 305 Japan \\ TAKASHI WAKAMATSU \\ Institute of Construction Technology \\ Kumagai Gumi, Tsukuba, Ibaraki, 305 Japan \\ Y. YOKOBAYASHI \\ Graduate School \\ Science University of Tokyo \\ Noda-City, Chiba, 278, Japan
}

\begin{abstract}
Experimental heat transfer and temperature correlations are presented for a steel beam installed beneath a ceiling when exposed to a localized fire source. The heat flux distribution on every part of the beam is formulated as a function of flame length and the distance from the fire source. A specially written finite volume code CV-FEM, as well as the general-purpose finite element code ANSYS were used for the numerical simulation. Experimental values of heat fluxes were applied as boundary conditions for the surfaces exposed to fire. The results of the three-dimensional transient thermal analysis obtained are compared with the experimental data. The program CV-FEM was found to be very effective for this type of problem. The experimental correlations obtained and numerical procedure developed can be used to predict the heating mechanism and thermal response of practical building members exposed to a localized fire.
\end{abstract}

KEYWORDS: localized fire, heat flux, finite volume, steel beam.

\section{NOMENCLATURE}

$C_{p}$ - specific heat of air $\left(\mathrm{J} \mathrm{kg}^{-1} \mathrm{~K}^{-1}\right)$

D - characteristic fuel size (m)
$\boldsymbol{H}_{\boldsymbol{B}} \quad$ - height between the burner surface and the bottom of the beam $(\mathrm{m})$ 
$\boldsymbol{H}_{\boldsymbol{C}}$-height from fire source to the ceiling (m)

$\boldsymbol{q}_{s}$ - heat flux at the stagnation point $\left(\mathrm{kW} \mathrm{m}^{-2}\right)$

$\boldsymbol{L}_{\boldsymbol{B}}$ - the length of the flame flowing along the lower surface of the beam (m)

$\boldsymbol{L}_{\boldsymbol{c}}$ - the length of the flame flowing under the ceiling $(\mathrm{m})$

$\boldsymbol{Q}$ - heat release rate $(\mathrm{kW})$

$Q^{*}$ - dimensionless heat release rate $\left(Q / C_{p} T_{0} g^{1 / 2} D^{5 / 2}\right)(-)$,

$Q_{D H B}^{*}=Q / \rho C_{P} T_{0} g^{1 / 2} D H_{B}^{3 / 2}(-)$
$Q_{D H C}^{*}=Q / \rho C_{P} T_{0} g^{1 / 2} D H_{C}^{3 / 2}(-)$

$\boldsymbol{T}_{\boldsymbol{0}}$ - ambient temperature (K)

g -gravitational acceleration $\left(\mathrm{m} \mathrm{s}^{-2}\right)$

$z^{\prime}$ - location of virtual source $(\mathrm{m})$

$\vec{n}$ - external normal to a surface

$\rho$ - density of ambient air $\left(\mathrm{kg} \mathrm{m}^{-3}\right)$

$\sigma$ - Stefan-Boltzman constant $\left(\mathrm{W} \mathrm{m}^{-2} \mathrm{~K}^{-4}\right)$

C -specific heat capacity $\left(\mathrm{J} \mathrm{kg}^{-1} \mathrm{~K}^{-1}\right)$

$\lambda$-thermal conductivity $\left(\mathrm{W} \mathrm{m}^{-1} \mathrm{~K}^{-1}\right)$

$\mathrm{S}$ - a source term in the heat transfer equation

\section{INTRODUCTION}

Although steel structures are required to be protected with thermal insulation in conventional fire safety design, there is a strong demand from the construction industry to use unprotected or weakly protected structures [1]. There are many examples where building elements are submitted to a localized heating during fire. If only a small part of a structure is exposed to fire, its fire resistance may be significantly different from that obtained assuming uniform temperature distribution. We believe that the main reason why only uniform heating was considered when analyzing structures' behaviour in fire, is that the only means of evaluations were standard fire resistance tests on single elements. With the introduction of performance based fire resistance codes in some countries, the general thermal and structural calculations of entire assemblies are explicitly foreseen. It is unrealistic to suppose the entire structure to be submitted to the uniform fire. If we consider such structures as atriums, parking buildings, railway stations etc. in terms of fire safety design, even if a fire should occur, the fire load would be comparatively small, because the compartment of such structures and the openings provided in them are sufficiently large. In such cases, any fire would be of a fuel-controlled type and the effect of heating on structural members could be localized. It may be assumed that the rise in temperature is smaller than in the event of all the members being subjected to heating by fire. When a metal structural member is heated only locally in a fire, the temperature of the member will rapidly even out due to the accelerated heat conduction through the member itself. Therefore, in the case where a load bearing member is heated only locally in fire, if a new method is established which can accurately predict the temperature of the components, the fire safety design will become more rational.

There are almost no works dealing with modeling of heating condition by a localized fire. There are many experimental and theoretical works on evaluating the activation of fire detectors and automatic sprinklers [2,3]. These investigations confirm that heat flux distributions in the ceiling are dominated by the heat release rate, the distance from the fire source to the ceiling and the burner size [4]. The distribution of heat flux on a ceiling above a localized fire as a function of the factors mentioned above has been presented in [5], but in the case of an $\mathrm{H}$-section steel beam installed beneath a ceiling, the heat flux distribution will be different at each cross-section of the beam. In view of the above mentioned points, the 
purpose of this study is to develop a new engineering method which can predict the thermal response of a bare steel beam exposed to a localized fire, based on the correlation of heat fluxes measured in the experiment. In this study, the total heat flux and temperature distribution on a bare steel beam beneath a ceiling are measured experimentally for heat release rates of $95-900 \mathrm{~kW}$ and a distance from the fire source to the beam of 0.6-1.2 $\mathrm{m}$. The paper deals with various types of heating conditions which may be imposed for actually used building members when they are exposed to a localized fire; for example, fire in a car under the beam in an open car park. The paper presents a summary of experimental and numerical results of a Research Project conducted at the Building Research Institute of Japan $[6,7,8]$.

\section{EXPERIMENTAL SETUP}

The experimental layout is shown in Figure 1. The rectangular flat ceiling consists of two layers of $12 \mathrm{~mm}$ thick mineral fiber Perlite board with dimensions $1.83 \times 3.60 \times 0.024 \mathrm{~m}$. The ceiling is reinforced by a steel frame and is horizontally placed over the beam held by two steel vertical posts at the ends. H-section bare steel beam with the following dimensions was used: $3.6 \mathrm{~m}$ long, $75 \mathrm{~mm}$ width, $150 \mathrm{~mm}$ height, $5 \mathrm{~mm}$ (thickness of web), $6 \mathrm{~mm}$ (thickness of flange). The height of the beam and the ceiling was adjusted by lifting these specimens up and down the posts. Heat flux measurements were made at nine horizontal distances from the stagnation point of the beam. Water-cooled Schmidt-Boelter heat flux gauges were installed flush with the beam surface through the holes made in the beam shown in Figure 2. The heat flux to the upper flange, web and also lower and upper surfaces of the lower flange was measured. Temperature measurements were made with thermocouples at 27 points, arranged symmetrically to the points of the heat flux gauges with regard to the center of the beam. Thermocouples were $0.2 \mathrm{~mm} \mathrm{~K}$-type and were installed $0.5 \mathrm{~mm}$ from the beam surface, as shown in Figure 3. A $0.5 \mathrm{~m}$ diameter round porous burner and a $1.0 \mathrm{~m}$ square porous burner were used as the fire source. These burners used propane as the fuel, and were regulated to distribute the flame uniformly.

\section{TEST CONDITIONS}

The experimental study of a flat ceiling above a localized fire source [4,5] makes it clear that the heat flux $\left(\mathrm{q}_{\mathrm{s}}\right)$ at the stagnation point depends on dimensionless height $\left(L_{f} / H\right) .(H)$ is the ceiling height and $\left(L_{f}\right)$ is the height of unconfined flametips. On the other hand $\left(L_{f}\right)$ is controlled by

$$
Q^{*} \equiv Q / \rho C_{P} T_{0} g^{1 / 2} D^{5 / 2}
$$

and $\left(L_{f}\right)$ is calculated with the estimated heat output using

$$
L_{f}=3.5 Q^{*^{n}} \cdot D
$$

where $\mathrm{n}=2 / 5$ for $Q^{*} \geq 1.0$ and $\mathrm{n}=2 / 3$ for $Q^{*}<1.0[9,10]$. 
From the result of the experiments on the flat ceiling mentioned above [5], we can see that there was an increase of heat flux $\left(\mathrm{q}_{\mathrm{s}}\right)$ at the stagnation point between $L_{f} / H=1.0$ and $L_{f} / H=2.5$. We believe that the importance and advantage of the consideration of localized fire becomes most significant in this domain. Considering this result, nine combinations of $Q, D$ and $H_{B}$ have been chosen as the experimental conditions of the steel beam test. The specific test conditions are shown in Table 1 . This experiment can be regarded as a model experiment with a scale $1 / 3$ relative to a typical cross-sectional dimension of realistic steel beams common in Japanese buildings.

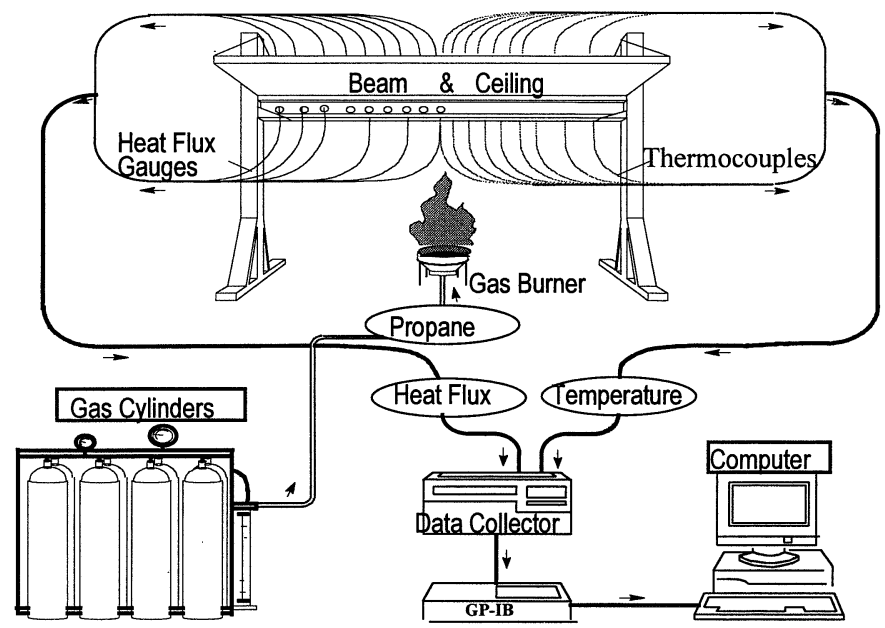

FIGURE 1 Experimental layout

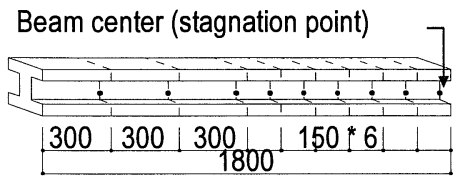

Locations of heat flux measurement, $\mathrm{mm}$

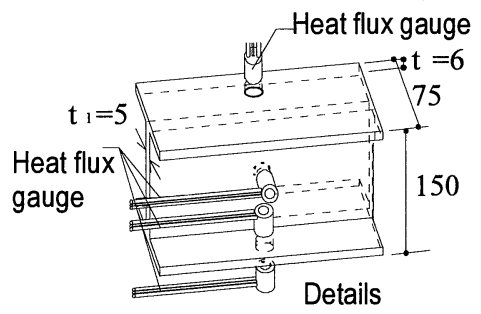

FIGURE 2 Arrangement of heat flux gauges on beam specimen

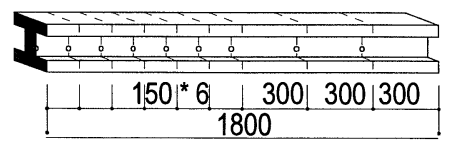

Locations of temperature measurement

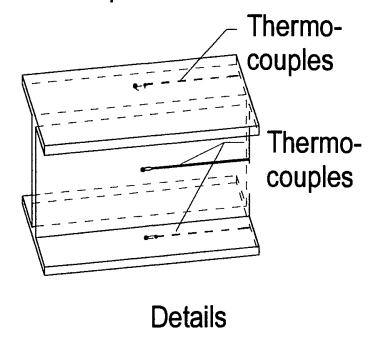

FIGURE 3 Arrangement of thermocouples 
TABLE 1. Test conditions

\begin{tabular}{|c|c|c|c|c|}
\hline Burner Size D $(\mathrm{m})$ & Heat Release Rate Q $(\mathrm{kW})$ & Distance $(\mathrm{m})$ & $\mathrm{Q}^{*}(-)$ & $\mathrm{L}_{\mathrm{f}} / \mathrm{H}_{\mathrm{B}}(-)$ \\
\hline \multirow{3}{*}{0.5} & 100 & 1.0 & 0.51 & 1.111 \\
(diameter, round burner) & 150 & 1.0 & 0.76 & 1.456 \\
& 200 & 1.0 & 1.01 & 1.754 \\
\cline { 2 - 5 } & 95 & 0.6 & 0.48 & 1.790 \\
& 130 & 0.6 & 0.66 & 2.201 \\
& 160 & 0.6 & 0.81 & 2.535 \\
\hline \multirow{3}{*}{1.0} & 540 & 1.2 & 0.48 & 2.155 \\
(square burner) & 750 & 1.2 & 0.67 & 2.682 \\
& 900 & 1.2 & 0.81 & 3.029 \\
\hline
\end{tabular}

\section{RESULTS}

\section{Heat Flux at the Stagnation Point}

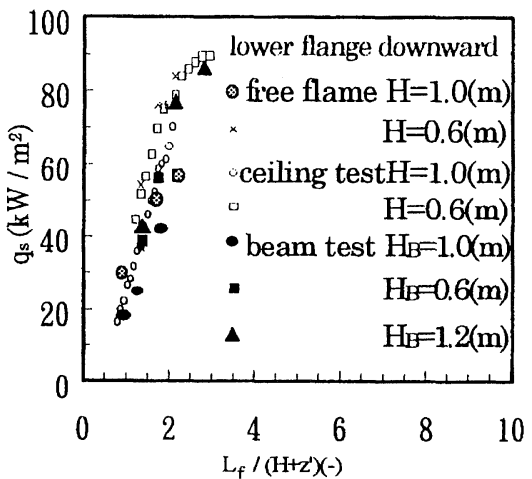

FIGURE 4 Relation between $\mathrm{q}_{\mathrm{s}}$ and $L_{f} /\left(H_{B}+z^{\prime}\right)$ at the stagnation point
The correlation between the $L_{f} /\left(H_{B}+z^{\prime}\right)$ and the heat flux to the lower surfaces of lower flange at the stagnation point is shown in Figure 4. For reference, the heat flux obtained at the flat ceiling test and the upward heat flux at the centerline from unconfined flames are also shown in Figure 4. The height of the beam $\left(H_{B}\right)$ is corrected with $\left(z^{\prime}\right)$, which is represented by using the empirical virtual source depth formula [10].

$$
\begin{array}{ll}
z^{\prime}=2.4 D\left(Q^{* 2 / 5}-Q^{* 2 / 3}\right) & \left(Q^{*}<1\right) \\
z^{\prime}=2.4 D\left(1-Q^{* 2 / 5}\right) & \left(Q^{*} \geq 1\right)
\end{array}
$$

With the experimental conditions of $H_{B}=1 \mathrm{~m}$ and $0.6 \mathrm{~m}$, the measured heat flux to the beam at the stagnation point is generally lower than the heat flux obtained in the flat ceiling test and the heat flux from the unconfined flame. In the case of $H_{B}=1.2 \mathrm{~m}$, the heat flux to the beam is nearly equal to that obtained in the flat ceiling test.

\section{Heat Flux and Temperature Distribution}

It was shown in [7] that the heat flux distributions along the beam at different cross-sectional locations decrease along the axial direction. In the near field of the stagnation point, there is 
more than three times the difference in heat flux between the lower flange and the upper flange for the same experimental condition. The gradient of incident heat flux is larger in the vertical direction than in the axial direction within the beam. However, the temperature distribution in the steel beam is rather uniform in comparison with the heat flux distribution. This difference suggests that heat conduction through the member of high thermal conductivity itself contributes to keeping the exposed part cooler.

\section{Relation between Heat Flux and Flame Length}

Although heat transfer to the flat ceiling was controlled primarily by the flame length beneath the ceiling [5], two kinds of flames were observed in the beam test. One flows along the lower surface of the beam $\left(\left(L_{B}\right)\right.$ as the length) and the other flows beneath the ceiling $\left(L_{C}\right)$ as shown in Figure 5. This phenomenon suggests that the factor controlling heat flux distribution on the beam differs from the case of the ceiling test. It is probably necessary to consider the effect of $\left(L_{B}\right)$

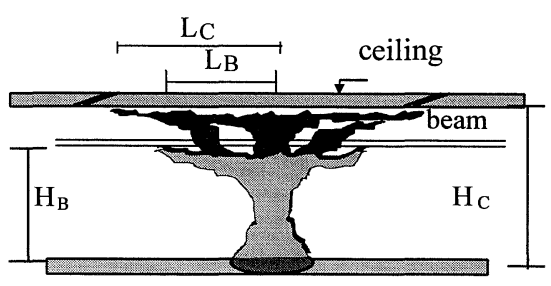
for heat transfer to the lower surface of the lower flange and $\left(L_{C}\right)$ for the other part of the beam. Figure 6 is a summary of the relation between $\left(L_{B}\right)$ and the dimensionless heat release rate $Q^{*}{ }_{D H B}$ with $\left(H_{B}\right)$ as a characteristic length-scale.

$Q_{D H B}^{*} \equiv Q / \rho_{0} C_{P} T_{0} g^{1 / 2} D H_{B}^{3 / 2}$

Similarly, the relation between $\left(L_{c}\right)$ and the dimensionless heat release rate $Q_{D H C}^{*}$ with $\left(H_{c}\right)$ as a characteristic length-scale are shown in Figure 7. The flame length $\left(L_{B}\right)$ and $\left(L_{C}\right)$ obtained from videotape were used for plotting the data. However, since it was impossible to take an accurate measurement of flame lengths with experimental conditions of $\left(H_{B}\right)=1.2 \mathrm{~m}$, these conditions were omitted. $\left(L_{B}+H_{B}\right)$ approached the plateau in the domain of $Q_{D H B}^{*}>0.3$, whilst $\left(L_{C}+H_{C}\right)$ increases in proportion to $Q_{D H C}^{*}$. Based on these data, the flame lengths $\left(L_{B}\right)$ and $\left(L_{C}\right)$ closely matched the formulae:

$$
\begin{aligned}
& L_{B}=H_{B}\left(1.82 Q^{*}{ }_{D H B}^{0.30}-1\right) \\
& L_{C}=H_{C}\left(2.04 Q^{*}{ }_{D H C}{ }^{0.33}-1\right)
\end{aligned}
$$

\section{Heat Flux to the Beam Surfaces}

Kikuchi and Hasemi have shown that the heat flux to a ceiling exposed to a room corner fire can be represented as a function of the radial distance from the stagnation point $(r)$ and the horizontal flame length of the flame beneath the ceiling $\left(L_{C}\right)$ [10]. 


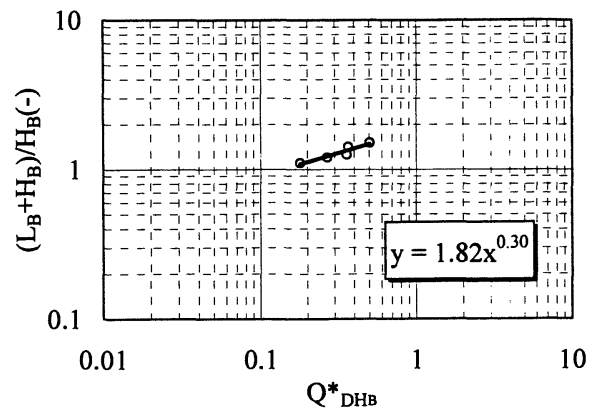

FIGURE 6 Relation between $Q_{D H B}^{*}$ and $\left(L_{B}+H_{B}\right) / H_{B}$

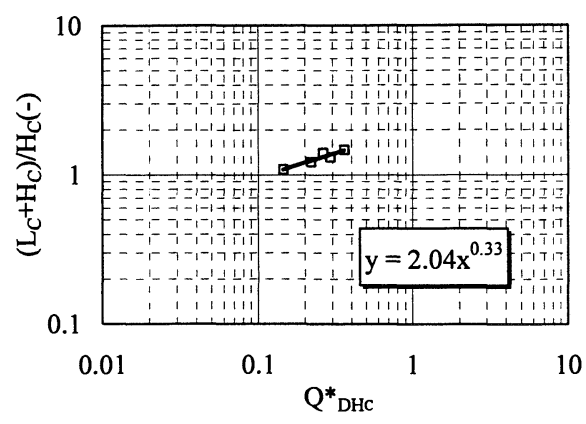

FIGURE 7 Relation between $Q_{D H C}^{*}$ and $\left(L_{C}+H_{C}\right) / H_{C}$

Applying these correlations, Figure 8 demonstrates the relation between the heat flux to the downward surface of the lower flange and the radial distance from the stagnation point which is normalized by the flame length $\left(L_{B}\right)$ and virtual source depth $(z ')$. The data is scattered more significantly in the range of $\left(r+H_{B}+z^{\prime}\right) /\left(L_{B}+H_{B}+z^{\prime}\right)>1$, where no flame exists, than in the range of $\left(r+H_{B}+z^{\prime}\right) /\left(L_{B}+H_{B}+z^{\prime}\right)<1$, where flame exists. The gradient of heat flux is larger for the experimental conditions of $H=0.6 \mathrm{~m}$ than $H=1.0 \mathrm{~m}$. This difference may be caused by the fact that the increase of the flame length $\left(L_{B}\right)$ becomes insignificant as $Q_{D H B}^{*}$ is increased in the domain of $Q_{D H B}^{*}>0.3$ as shown in Figure 6. The value of $Q_{D H B}^{*}$ is $0.09-0.18$ for the experimental conditions of $H_{B}=1.0 \mathrm{~m}$, and $Q_{D H B}^{*}$ is $0.31-0.54$ for the experimental condition of $H_{B}=0.6 \mathrm{~m}$ and $1.2 \mathrm{~m}$ for reference.

Figures 9 demonstrates the relation between the heat flux to the web and the radial distance from the stagnation point, whilst Figure 10 shows this information for the upward surface of the lower flange. Both data sets are scattered significantly in the domain where no flame exists. The heat flux to the web and upward surface of the lower flange are generally lower than the heat flux to the downward surface of the lower flange. Both sets of flux values are concentrated along a broken line corresponding to the minimum heat flux observed in the ceiling test. It is also noteworthy that the heat flux to the web is generally larger than the heat flux to the upper surface of the lower flange. This is probably because of the radiation from the flame developing horizontally beneath the ceiling.

Heat flux distributions to the downward surface of the upper flange are shown in Figure 11. The data's unevenness is no more significant in any range of $\left(r+H_{B}+z^{\prime}\right) /\left(L_{B}+H_{B}+z^{\prime}\right)$ than in any other part of the beam, and is generally lower than the broken line corresponding to the minimum heat flux observed in the ceiling test. 




FIGURE 8 Lower Flange downward

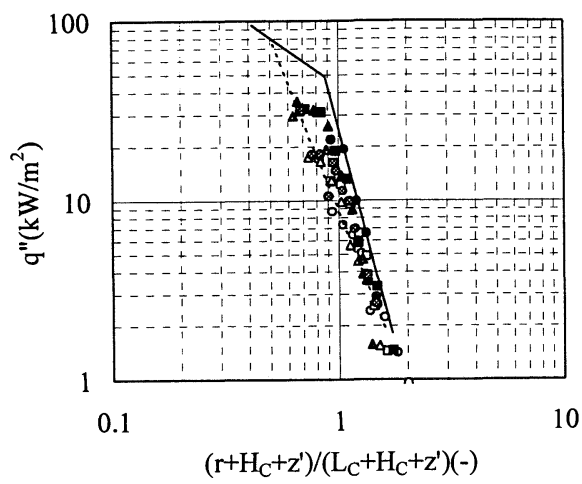

FIGURE 10 Lower flange upward
(1) $\mathrm{H}=1.2 \mathrm{~m}, \mathrm{Q}=540 \mathrm{KkW} \longrightarrow$ Flat Ceiling Maximum $\mathrm{Q}=900 \mathrm{k}$

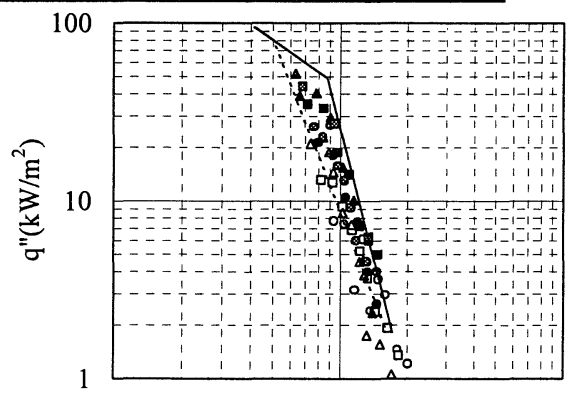

0.1 10

FIGURE 9 Web

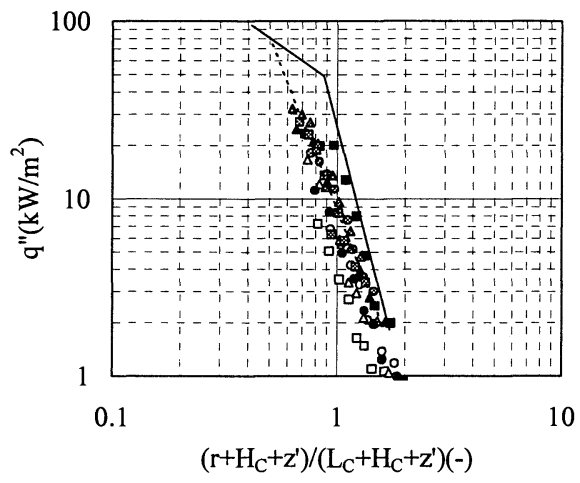

FIGURE 11 Upper Flange downward

\section{Radial Heat Flux Distribution}

\section{NUMERICAL SIMULATION BY ANSYS}

The ANSYS finite element code was used for thermal transient three-dimensional analysis of beam +ceiling assemblies $[8,14]$. Heat flux values obtained in the experiments were used as boundary conditions for the heated surfaces of the model. Reradiation from heated surfaces and also convection and radiation loss from unexposed to fire surfaces were considered. Resultant emissivities of 0.9 were used for both exposed and unexposed surfaces. A convection factor of $2.2 \mathrm{~W} / \mathrm{m}^{2} \mathrm{~K}^{5 / 4}$ and convection power of 1.25 were assumed for the unexposed surface [6]. Temperature dependent material properties, similar to those used in [6], were considered in the simulation. The heat transfer at the boundaries was defined using 
special surface elements SURF22 from the ANSYS element library. The beam and ceiling were modeled using 8-node brick elements SOLID70. There were 38 divisions along the beam's length and 8 divisions along its depth.

It was necessary to eliminate the error in input flux values caused by the difference in temperature between a heat flux gauge's $\left(T_{g}\right)$ and the surface of the specimen $\left(T_{\mathrm{s}}\right)$. Previous experiments [11] suggest that the heat flux to the specimen's surface can be estimated with a relatively small error by taking $h\left(T_{S}-T_{g}\right)$ from the experimental values of heat fluxes. It was found in [11] that the heat transfer coefficient $h$ varied from 0.03 to $0.04 \mathrm{~kW} / \mathrm{m}^{2} \mathrm{~K}$ for the range of the heat fluxes studied. According to the procedure by which the coefficient $h$ was obtained, it included both radiative and convective terms. In the present study, the radiative part of heat transfer from the heated surfaces was considered in the numerical procedure, therefore we had to correct only the convective one. Another notation, namely $h_{c}$ instead of $h$, was used to highlight the difference. The value of $h_{c}$ was obtained by a trial and error procedure, matching experimental and numerical results for tests of a flat ceiling above a fire source: these had been conducted prior to the tests with beam/ceiling assemblies. By varying the $h_{c}$ coefficient, it has been found that values of $0.01--0.02 \mathrm{~kW} / \mathrm{m}^{2} \mathrm{~K}$ gave the best match with the test results. These values were then used for the beam tests.

\section{NUMERICAL SIMULATION BY CV-FEM.}

A modification of the finite volume method was used to solve the three-dimensional heat transfer equation. The method is readily applicable for the calculation domains formed by transition of a plane section along the generating lines in Cartesian or cylindrical coordinate systems. The method can be considered as a continuation of the method [12] which was developed for parabolic flows to elliptic problems in the calculation domains of the same type. To obtain the discrete equations, grid points are imposed at the domain. The grid points are obtained by finite element discretization at the sections normal to the longitudinal axis. Then the domain is divided into a number of nonoverlapping finite volumes in such a way that there is one finite volume surrounding each grid point. Details of the discretization procedure are described in ref. $[8,12,13]$. Discrete equations for every node of the domain in which a solution is desired form a system of linear algebraic equations with a symmetric, positively defined and diagonally predominant matrix. This makes it possible to use highly effective iterative solution methods. In the case where the heat transfer equation is nonlinear, an iterative procedure is used. The numerical procedure was implemented in the code CV-FEM, written in the FORTRAN 77 language.

\section{RESULTS AND DISCUSSION}

The CV-FEM code was used to calculate temperature fields in the beam/ceiling assemblies. Boundary conditions, properties of materials and the correction coefficient $h_{c}$ were chosen in exactly the same way as in the calculations with the ANSYS code. A special study was conducted to determine the influence of the time step and different mesh discretization on the accuracy of the results obtained. The varying parameters were the time step $\Delta \tau$ and the number of nodes in a cross section of the beam, $N_{1}$, and along its longitudinal axis, $N_{2}$. Table 
2 illustrates that for the presented range of the parameters, there is very weak variability of the calculated lower flange temperature. The results correspond to the 130-0.6 test.

TABLE 2. Influence of time step and number of divisions on the accuracy of results

\begin{tabular}{|c|c|c|c|c|c|}
\hline Time step $\Delta \tau(\mathbf{s e c})$ & $\mathbf{0 . 1}$ & $\mathbf{1 . 0}$ & $\mathbf{1 0 . 0}$ & $\mathbf{1 . 0}$ & $\mathbf{1 0 . 0}$ \\
\hline Number of divisions $\mathbf{N}_{1} \times \mathbf{N}_{\mathbf{2}}$ & $79 \times 21$ & $79 \times 21$ & $79 \times 21$ & $241 \times 41$ & $241 \times 41$ \\
\hline Distance (m) & \multicolumn{5}{|c|}{ Temperature (C) after 7 min of fire exposure } \\
\hline $\mathbf{0}$ & 573 & 572 & 570 & 570 & 568 \\
\hline $\mathbf{0 . 1 8}$ & 506 & 505 & 503 & 503 & 502 \\
\hline $\mathbf{0 . 3 6}$ & 332 & 332 & 330 & 329 & 329 \\
\hline $\mathbf{0 . 7 2}$ & 120 & 120 & 119 & 118 & 119 \\
\hline $\mathbf{1 . 0 8}$ & 74.5 & 74.4 & 74 & 73.8 & 74 \\
\hline $\mathbf{1 . 4 4}$ & 50 & 50 & 50 & 49 & 49.5 \\
\hline
\end{tabular}

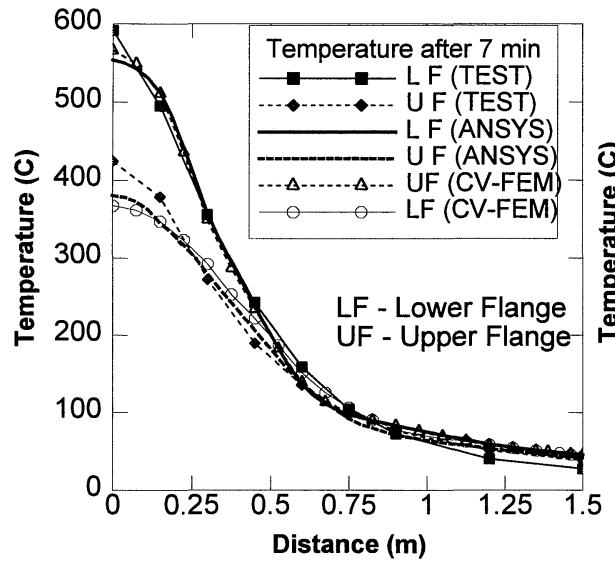

FIGURE 12 Lower and upper flange experimental and calculated temperatures (beam 130-0.6)

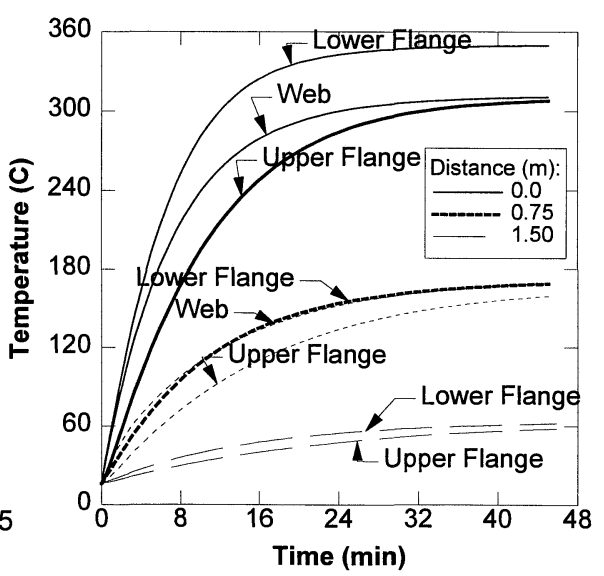

FIGURE 13 Time-temperature history (beam 100-1)

Comparison of calculated and measured lower flange temperature along the beam's length is shown in Figure 12 for the test 130-0.6. There is quite a good agreement between calculation by ANSYS, CV-FEM and the experimental results. In the region of the stagnation point, calculated values are usually higher. This can be partially explained because of the systematic error caused by the experimental procedure. The thermocouple used to measure temperature at the stagnation point was located very close to a heat flux gauge. Due to the low temperature of the gauge's surface, some errors in the temperature measurements are possible. The timetemperature history for the various cross-sectional locations of beams BM-100-1 is shown in 
Figure 13. The duration of the experiment was equal to $20 \mathrm{~min}$. It can be found from Figure 13 that in the case of beam BM-100-1, steady-state conditions were not reached after 20 min of fire exposure. This means that results of the steady-state calculations are over conservative.

\section{CONCLUSIONS}

1. The heat flux to the lower surfaces of the lower flange at the stagnation point is generally lower than the heat flux obtained in the flat ceiling test and the heat flux from an unconfined flame with an identical $L_{f} / H$ condition.

2. The difference in heat flux and temperature between the lower flange and the upper flange suggest that heat conduction through the member itself, due to the high thermal conductivity of the metal, contributes to keeping the exposed part cooler.

3. The heat flux distribution on the beam and the flame shape under the ceiling differ from the case of the ceiling test. Heat transfer to the lower surface of the lower flange is controlled primarily by $\left(L_{B}\right)$ and the other part of the beam is controlled by $\left(L_{C}\right)$. Using these relations, the heat flux distribution on every part of the beam can be represented as a function of flame length $\left(L_{B}\right)$ or $\left(L_{C}\right)$ and the height $\left(H_{B}\right)$ or $\left(H_{C}\right)$ with a correction based on the virtual source to an error within $20 \%$. These flame lengths become a function of the heat release rate normalized by the height $\left(H_{B}\right)$ or $\left(H_{C}\right)$ as a characteristic scale-length.

4. The numerical procedure and the "hybrid" finite-volume finite-element code CV-FEM have been developed.

5. The results of the calculations were found to be in a good agreement with the experimental results and with the results obtained using ANSYS finite element code.

The range of these experiments includes the heating conditions typical of parking-lot fires, in which structures are exposed to a localized fire from a burning car. The results of this study can be used to predict the heating mechanism and thermal response of practical building members exposed to a localized fire.

\section{ACKNOWLEDGMENTS}

This research program was conducted under partial support of the Kozai (Steel) Club of Japan. The authors wish to thank Messrs. T.Nakazato and S.Nakagawa of the Kozai Club for the arrangement of the support. Research activity of Dr. A.Pchelintsev was partially supported by the STA Fellowship, with Building Research Institute as the hosting organization.

\section{REFERENCES}

1. Sakumoto,Y.: New Materials and New Methods of Fire Resistance of Steel-Frame Construction, Kankoku Publishers, Ltd.,1994 (in Japanese).

2. You,H.Z., Fathe,G.M.: An Investigation of Fire Impingement on a Horizontal Ceiling, Report for NBS, 1979. 
3. Hasemi,Y., Sako,S., :Response Time of Automatic Sprinklers below a Confined Ceiling, Proceedings of the Second International Symposium on Fire Safety Science, Tokyo, 1988.

4. Kokkala,M. : Experimental Study of Heat Transfer to Ceiling from an Impinging Diffusion Flame, Proc. Third International Symposium on Fire Safety Science, Edinburgh, 1991.

5. Cetegen,B., Zukoski,E.E., Kubota,T. : Entrainment and Flame Geometry of Fire Plumes, NBS-GCR-82-402, 1982.

6. Hasemi,Y., Yokobayashi,Y., Wakamatsu,T., Ptchelintsev,A., Firesafety of Building Components Exposed to a Localized Fire -- Scope and Experiments on Ceiling/Beam System Exposed to a Localized Fire, Proceedings of the ASIAFLAM '95, Hong Kong, pp.351-361, 1995.

7. Wakamatsu,T., Hasemi,Y., Yokobayashi,Y., Ptchelintsev,A., Experimental Study on the Heating Mechanism of a Steel Beam Under Ceiling Exposed to a Localized Fire. Proceedings of the INTERFLAM '96 Conference, pp. 509-518, Cambridge, England, 1996.

8. Ptchelintsev,A., Hasemi,Y., Nikolaenko,M., Skibin,A., Wakamatsu,T., Threedimensional thermal analysis of steel beams exposed to a localized fire. Proceedings of the INTERFLAM'96 Conference, pp. 519-529, Cambridge, England, 1996.

9. Hasemi,Y., and Tokunaga,T., Flame Geometry Effects on the Buoyant Plumes from Turbulent Diffusion Flames, Fire Science and Technology, Vol.4, No.1, 1984.

10. Kikuchi,R., Hasemi,Y., Takashima,S., Yoshida,M., Yokobayashi,Y. and Wakamatsu,T. Heating Mechanism of the Surface of Interior Linings by an Open Corner Fire, JAFSE Annual Meeting, 1994.

11. Hasemi,Y., Yoshida,M. and Nakabayashi T., Effectiveness of Noncombustible Ceiling for the Improvement of Fire Safety in a Compartment Finished with Wood, Journal of Structural and Construction Engineering, Transactions of AIJ, No. 446, 1993 (in Japanese).

12. Prakash,C., Patankar,S.V., A Control-volume Finite-Element Method for Predicting Flow and Heat Transfer in Ducts of Arbitrary Cross Sections - Part I: Description of the Method. Numerical Heat Transfer, 1987, vol.12, pp. 389-412.

13. Nigmatullin,B., Glebov,S., Makarov,D., Skibin,A., Yugov,V., Development of the Software Based on a Hybrid Control Volume Method for the Application to NPS Thermal Problems. Preprint ENIC L11/24-1996.1. Elektrogorsk, 100 pp, 1996. (in Russian).

14. ANSYS User's Manual for Revision 5.0. Swanson Analysis Systems, Inc., February 1994. 